\title{
Perfil intra-empreendedor: um estudo inicial em funcionários da Infraero-sede
}

Eliana Pessoa e Kelly Cristina Nóbrega Oliveira

\section{Introdução}

Vive-se uma época de mudança de paradigmas: a atual sociedade se depara com a era do conhecimento. Para atender às novas demandas, é necessário saber o que se deve aprender, além de saber utilizar esse conhecimento. A inovação e o espírito empreendedor despontam como as principais práticas para sobreviver atualmente. Para os indivíduos, essas atitudes são primordiais, pois são elas as mais exigidas para a sua atuação profissional. As empresas também necessitam incorporar uma cultura empreendedora, pois somente assim conseguirão atender às exigências do mercado e vencer os obstáculos advindos da mudança de paradigma.

Não somente as empresas privadas estão se adequando. Órgãos governamentais e empresas públicas também precisam se modernizar. Mudanças significativas na gestão pública brasileira têm ocorrido nos últimos anos, na busca de atender com qualidade ao cidadão e às necessidades do governo. É o caso da Empresa Brasileira de Infra-Estrutura Aeroportuária (Infraero), responsável pela 
administração de aeroportos em todo o Brasil, que, mesmo sendo empresa pública, encontra-se em um ambiente altamente competitivo. Os grandes desafios da Infraero são adaptar-se ao ambiente repleto de mudanças e atender às crescentes exigências dos usuários de transporte aéreo, das empresas áreas, das empresas de serviços auxiliares e dos órgãos de fiscalização da aviação civil, além de buscar o cumprimento das metas do governo. A Infraero também está envolvida no processo de internacionalização, por isso está se inserindo em mercados com características diversas e com exigências ainda mais complexas. Recentemente, a empresa estabeleceu parcerias e firmou acordos de cooperação técnica para prestar consultoria a diversos aeroportos da América do Sul, além dos EUA, Angola, China e Portugal.

Para tanto, percebeu-se a necessidade de saber se a empresa possui colaboradores dotados de certas características que denotam o potencial intra-empreendedor. Foi realizada, com base nesse contexto, pesquisa de campo nos meses de maio e abril de 2005, cujo objetivo principal foi identificar se os funcionários da empresa possuem perfil intra-empreendedor, para que possam melhor colaborar com a organização e buscar sua auto-realização. Essa análise foi feita por meio de um instrumento de perfil do intra-empreendedor, contendo 28 pares de afirmativas, que representam as necessidades e habilidades do intra-empreendedor de sucesso.

\section{Dados da organização}

A Infraero é uma empresa pública de direito privado, responsável pela administração operacional, comercial e gerencial de aeroportos. Em consonância com as orientações do governo federal, a Infraero passou a operar, em 2003, como instrumento de implementação das políticas públicas necessárias ao restabelecimento do crescimento nacional, fortalecendo as práticas de gestão empresarial voltadas à segurança, conforto, qualidade e responsabilidade social e ambiental.

A empresa é responsável pela administração de 66 aeroportos e 81 estações de apoio à navegação aérea, constituindo-se em um dos segmentos do Sistema de Aviação Civil (SAC). Com sede em Brasília, está estruturada em oito superintendências regionais, que são sistemas descentralizados e responsáveis pelo planejamento, coordenação e execução dos serviços de infraestrutura aeroportuária e de navegação aérea, às quais estão vinculados os aeroportos, os grupamentos de navegação aérea e as unidades técnicas de aeronavegação.

De acordo com o Relatório de Administração (INFRAERO, 2005), os aeroportos administrados pela Infraero concentram 97\% do movimento do transporte aéreo regular no Brasil, o que equivale a 1,8 milhão de pousos e decolagens de aeronaves nacionais e estrangeiras, transportando aproximadamente 71,2 milhões de passageiros e 1,2 milhão de toneladas de carga, anualmente.

\section{Referencial teórico}

\section{Origens e conceitos do empreendedorismo}

A palavra empreendedorismo provém do francês entrepreneur. Era usada no século XII para designar aquele que incitava brigas e também para denominar pessoas envolvidas em operações militares. Em 1730, Cantillon usou entrepreneur "para designar uma pessoa que trabalhava por conta própria e tolerava o risco no intento de promover 
seu próprio bem-estar econômico" (ÂNGELO, 2003, p. 25).

No início do século XIX, o economista Jean-Baptiste Say definiu o empreendedor como "um individuo que transfere recursos econômicos de um setor de produtividade baixa para outro de elevada produtividade e de maior rendimento" (Dias, 2001, p. 42). No início do século XX, Schumpeter (apud Aıub, 2002, p. 34) designou o empreendedor como:

“...o responsável pelo processo [...] de destruição criativa, sendo o impulso fundamental que aciona e mantém em funcionamento a economia capitalista, constantemente criando novos produtos, novos métodos de produção, novos mercados e implacavelmente, sobrepondo-se aos antigos métodos, menos eficientes e mais caros."

Não só os economistas buscaram entender o significado e a importância do empreendedorismo. Os comportamentalistas estudaram o assunto sob o aspecto da figura do empreendedor, suas necessidades, características, hábitos, atitudes e ações. Segundo McClelland (1967 apud BragA, 2003, p. 4) "existem sociedades que alcançaram um grande desenvolvimento porque possuiam um alto nivel de motivação para realização”. Para Drucker (1987 apud Cozzi; Arruda, 2004, p. 3) "qualquer indivíduo que tenha à frente uma decisão a tomar pode aprender a ser um empreendedor". Timmons (1994 ibidem) define o empreendedor como "alguém capaz de identificar, agarrar e aproveitar oportunidades, buscando e gerenciando recursos para transformar a oportunidade em negócio de sucesso".

Fillion (1991 apud Dolabela, 1999, p. 28) afirma que "um empreendedor é uma pessoa que imagina, desenvolve e realiza visões". Pela teoria visionária de Fillion o empreendedor, ao formar uma idéia sobre um produto, um serviço, ou seja, sobre um negócio, concebe a visão emergente. Para aprofundála, aprimorá-la e validá-la, busca informações com pessoas do ramo, ou através de livros, revistas, feiras, dentre outros. Quando chega à idéia final sobre o negócio está formada sua visão central, pela qual busca a sua realização.

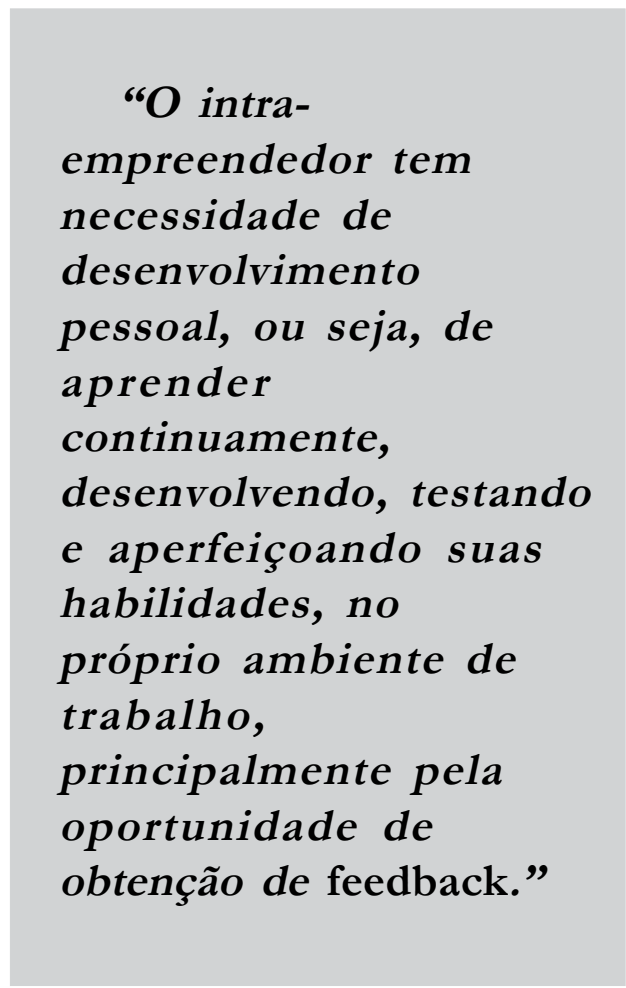

Dolabela (2005, p.2) amplia o conceito e propõe que "é empreendedor, em qualquer área, alguém que sonha e busca transformar seu sonho em realidade". Assim, empreendedor não é só aquele que abre uma empresa. Inclui também empregados empreendedores, empreendedores sociais e empreendedores coletivos. Este trabalho focalizará a figura do empreendedor corporativo, tão necessário nesse novo ambiente, em que o grande diferencial competitivo das empresas em relação aos concorrentes está na sua capacidade de 
inovar, de desenvolver novos produtos, de aumentar a produtividade, de atrair e reter clientes, de aproveitar as oportunidades que surgem.

\section{O empreendedor corporativo}

As organizações, nos últimos tempos, passaram a depender de atitudes empreendoras para sobreviver no mercado. O cenário mundial é turbulento, com mudanças bruscas, com comunicações rápidas e eficientes, constante desenvolvimento tecnológico, imprevisibilidade das economias e aumento do nível de exigência dos mercados. Anteriormente, as vantagens competitivas eram baseadas em custos baixos e qualidade nos produtos e serviços. Hoje, o diferencial competitivo é saber usar o conhecimento, gerando soluções inovadoras continuamente e aproveitando as oportunidades.

Para Pinchot (1985, citado por Cozzi; ArrudA, 2004, p. 4), "intra-empreendedorismo e inovação dependem de pessoas que trabalham na empresa, mesmo de grande porte, e agem como se fossem proprietários". Dornelas explica que "empreendedores corporativos são indivíduos ou grupos de indivíduos, agindo independentemente ou como parte do sistema corporativo, os quais criam as novas organizações ou instigam a renovação ou inovação dentro de uma organização existente"(2003, p.38).Ainda de acordo com Pinchot, "empreendedorismo não se trata somente de aumentar o nível de inovação e produtividade nas organizações tratase de uma forma de organizar vastas empresas, de modo que o trabalho volte a ser uma expressão alegre da contribuição da pessoa à sociedade" (PInchot, citado por ÂNGELO, 2003, p. 32).

Pode-se perceber que o intra-empreendedorismo é o exercício de atitudes empreendedoras dentro das organizações já estabelecidas. O empreendedor corporativo é aquele indivíduo que tem idéias e as transformam em realidades rentáveis à organização.

\section{Características do empreendedor corporativo}

Segundo Ângelo (2005, p.6), “o intraempreendedor deve pautar-se sempre pela busca da inovação, ainda que precise compatibilizar os interesses gerais $\mathrm{da}$ corporação, acionistas e investidores". Além disso, o empreendedor corporativo, ao agir, também busca sua realização pessoal e uma das principais recompensas esperadas pelo colaborador é o reconhecimento.

No ambiente interno, [o intra-empreendedor] "terá como atribuições mobilizar pessoas, aproveitar inteligentemente recursos materiais e financeiros [da organização] e (...) modificar hábitos e regularmente prestar contas de suas iniciativas" (ibidem).

O empreendedor corporativo é aquele que não é dono do negócio, porém, dentro de uma organização, desenvolve e realiza visões em prol da melhoria dos processos, fazendo com que a empresa aumente a sua produtividade. Dessa forma, cabe ao nível estratégico da empresa desenvolver e dar apoio a esse indivíduo, implementando políticas de avaliação e reconhecimento, de forma a fazer com que os obstáculos dos mercados competitivos sejam transpostos com total sucesso para organização.

Para que o profissional possa desenvolver o espírito empreendedor, é importante que ele tenha aspectos em sua personalidade que sejam compatíveis com as características do perfil empreendedor. Conforme Mori (apud URIARTE, 2000), as características de personalidade do 
empreendedor/intra-empreendedor podem ser agrupadas em quatro aspectos: necessidades, conhecimentos, habilidades e valores, como mostrado no quadro 1 . mento prévio do funcionamento da empresa.

- formação complementar: relacionase com a aquisição de novos conhecimentos

\section{Quadro 1: Principais características do empreendedor}

\begin{tabular}{|c|c|c|c|}
\hline Necessidades & Conhecimentos & Habilidades & Valores \\
\hline $\begin{array}{l}\text { - Aprovação } \\
\text { - Independência } \\
\text { - Desenvolvimento } \\
\text { Pessoal } \\
\text { - Segurança } \\
\text { - Auto-realização } \\
\text { - Vínculos }\end{array}$ & $\begin{array}{l}\text { - Aspectos técnicos } \\
\text { relacionados ao } \\
\text { negócio } \\
\text { - Experiência na área } \\
\text { - Escolaridade } \\
\text { - Experiência } \\
\text { emoresarial } \\
\text { - Formação } \\
\text { complementar } \\
\text { - Vivências com } \\
\text { situações novas }\end{array}$ & $\begin{array}{l}\text { - Identificação de } \\
\text { novas oportunidades } \\
\text { - Valoração de } \\
\text { oportunidades e } \\
\text { pensamento criativo } \\
\text { - Comunicação } \\
\text { persuasiva } \\
\text { - Negociação } \\
\text { - Aquisição de } \\
\text { informações } \\
\text { - Resolução de } \\
\text { - Alcançar metas } \\
\text { - Motivação e decisão }\end{array}$ & $\begin{array}{l}\text { - Existenciais } \\
\text { - Estéticos } \\
\text { - Intelectuais } \\
\text { - Morais } \\
\text { - Religiosos }\end{array}$ \\
\hline
\end{tabular}

Fonte: Mori (apud URIARTE, 2000)

Os conhecimentos são necessários ao empreendedor de sucesso, pois servem de base para a tomada de decisões. Longen (1997 apud AIUB, 2002) descreve os conhecimentos da seguinte forma:

- aspectos técnicos relacionados ao negócio: é necessário possuir o máximo possível de dados em relação aos produtos e serviços relacionados ao negócio.

- experiência na área: diz respeito às práticas relacionadas ao atendimento das necessidades dos clientes.

- escolaridade: refere-se aos conhecimentos adquiridos no sistema formal de ensino, que permitem ao empreendedor responder adequadamente às exigências do negócio.

- experiência empresarial: facilita a resolução de problemas, pois é um conheci- e com a atualização dos que já possui, a partir de um interesse particular ou de uma necessidade gerada pelo próprio negócio.

- vivência de novas situações : a passagem por mudanças é difícil, mas de grande aprendizagem, pois facilita a superação de problemas, dando uma nova visão ao empreendedor.

Valores para Gibson e outros (1981 apud MACEDo, 2003, p. 18) são "preferências, aversões, pontos de vista, deveres, inclinações internas, julgamentos racionais e irracionais, preconceitos e padrões de associação de uma pessoa". Os valores são classificados, segundo Empinotti (1994 apud Dias, 2001) como:

- existenciais: são relativos à saúde, à alimentação, ao lazer, entre outros. A empresa é a provedora de recursos, que possibilitam 
ao empreendedor ter acesso aos padrões de valores existenciais desejados.

- estéticos: estão relacionados à sensibilidade e irão refletir em cuidados com ordem, limpeza e disposição do ambiente de trabalho.

- intelectuais: refletem em ações como ritmo de inovação nas organizações e na maneira do empreendedor processar as informações.

- religiosos: mostram como o empreendedor se relaciona com as demais pessoas. Porém, o excesso e o fanatismo atrapalham as relações no ambiente de trabalho.

\section{Necessidades}

Segundo Chiavenato (2002), necessidade é um conjunto de motivos que leva o indivíduo a adotar determinado comportamento. Para Longen (1997, apud Dias, 2001) a necessidade de aprovação está relacionada com a conquista de status, respeito e prestígio. $\mathrm{O}$ intra-empreendedor tem a necessidade de reconhecimento por parte de seus superiores e pela própria sociedade, vontade de aumentar o status e de ser respeitado pelos amigos e pela família. Conforme Maslow (1968, apud DiAs, 2001 p. 65), “as pessoas mostram duas categorias relativas às necessidades de estima: a auto-estima e o respeito por parte dos outros".

Para tanto, o intra-empreendedor busca, constantemente, o sucesso de suas ações, para que possa ser reconhecido por isso. A valorização e o reconhecimento do intra-empreendedor, por sua vez, farão com que o funcionário se esforce cada vez mais para realizar ações merecedoras de aplausos.

Cozzi e Arruda (2004, p.11) enumeram como ação empresarial favorável ao clima empreendedor "a criação de programas de reconhecimento e recompensa com base em contribuições diferenciadas de indivíduos e equipes, de forma a estimular a conquista de metas desafiadoras".

O intra-empreendedor também tem a necessidade de independência e de liberdade para impor seu próprio enfoque de trabalho, obter flexibilidade em sua vida profissional e familiar e controlar seu próprio tempo. Dornelas (2003, p. 64) afirma que "eles querem estar à frente das mudanças e ser donos do próprio destino. Querem criar algo novo e determinar seus próprios passos, abrir seus próprios caminhos".

O empreendedor assume a posse completa de sua mente e a dirige para os objetivos que ele mesmo escolheu, sem permitir que influências externas o desestimulem ou desencaminhem. $\mathrm{O}$ indivíduo independente é, acima de tudo, autoconfiante.

O intra-empreendedor tem a necessidade de desenvolvimento pessoal, ou seja, de aprender continuamente, desenvolvendo, testando e aperfeiçoando suas habilidades. Estas últimas geralmente são testadas e aperfeiçoadas no próprio ambiente de trabalho, principalmente pela oportunidade de obtenção de feedback a respeito de seu desempenho, atitudes e comportamento no trabalho.

O feedback é importante para que o intraempreendedor saiba quais habilidades ele precisa desenvolver ou aprimorar. Dolabela (1999) considera que as organizações empreendedoras precisam dar feedback a seus funcionários de forma que seja: aplicável ,dirigido para o comportamento a ser modificado; neutro, sem tom de censura ou reprovação; específico voltado para uma dada situação; objetivo e claro. Além disso, recomenda que seja dado diretamente a quem ele diz respeito.

A necessidade de segurança, outra característica identificada no perfil 
intra-empreendedor, consiste na busca, dentro da empresa, de um meio seguro para empreender, testar e inovar, assumindo riscos calculados. O intra-empreendedor, apesar de gostar de certa segurança financeira, aceita correr riscos calculados, mesmo inconscientemente. Ele não se importa em iniciar projetos que possam pôr em risco seu emprego. A empresa adota procedimentos para satisfazer a necessidade de segurança quando possui gerências mais abertas, flexíveis e tolerante aos erros.

Dornelas (2003, p. 46) considera que "riscos calculados não necessariamente riscos pequenos, são riscos estudados, analisados e sabe-se o que pode acontecer com a organização caso o risco se torne realidade". Os empreendedores procuram identificar os riscos e tentam minimizá-los.

A necessidade de auto-realização, considerada por McClelland a característica mais presente no perfil intra-empreendedor, consiste na busca do intra-empreendedor da maximização de seu potencial e na visualização da empresa como um local onde suas capacidades podem ser utilizadas e aperfeiçoadas, obtendo assim uma realização pessoal. Por isso, está sempre buscando tarefas que desafiem suas capacidades físicas e intelectuais.

Pessoa e Goulart (2004, p. 9) afirmam que "as pessoas com alta necessidade de realização são aquelas que procuram mudanças em suas vidas, estabelecem metas realistas e realizáveis e colocam-se em situações competitivas".

A necessidade de vínculos, para Pinchot (1989, apud URIARTE, 2000, p. 42) significa que "para o intra-empreendedor, a organização em que trabalha é um ótimo local para aplicar suas idéias e buscar a autorealização”. O intra-empreendedor com necessidade de vínculos geralmente se envolve com as atividades na sua empresa pela paixão pelo que faz (MoreIrA, 2004, p. 3). O sentimento de vínculo faz com que o intra-empreendedor canalize todas as suas energias, habilidades e idéias para serem utilizadas em prol da organização em que trabalha.

\section{Habilidades}

Uma das características dos intraempreendedores é a habilidade de identificação de novas oportunidades. Dornelas (2003, p. 36) afirma que "o empreendedorismo é dirigido à identificação, avaliação e captura de oportunidades de negócios". Existem diversas fontes de oportunidades que podem ser verificadas pelo intra-empreendedor. McMillian e Block (1997, citados por BIRLEY; MUZYKA, 2001) indicam três fontes: internas, externas e mudanças no setor de mercado.

As fontes internas de oportunidades podem ser encontradas a partir da análise dos processos, da estrutura organizacional, das relações internas ou de qualquer outro elemento que possa ser corrigido, melhorado ou complementado. Segundo Drucker (1985, citado por BirLEY; MuZYKA, 2001, p. 270), "as mudanças são uma grande fonte de oportunidades". Essa fonte está diretamente ligada às demandas do mercado, à entrada de novos concorrentes, entre outros. $\mathrm{O}$ ambiente externo proporciona oportunidades, mas também gera ameaças. Alguns exemplos de forças externas que podem influenciar uma organização são mudanças demográficas, no estilo de vida, nos valores, nos regulamentos governamentais, problemas sociais, conjuntura econômica, entre outros.

A habilidade de identificar novas oportunidades é natural do intra-empreendedor. Ray (1993, citado por MACEDO, 2003 p. 17) afirma que o empreendedor tem "a habilidade de perceber o que os 
outros não percebem e de visualizar muito mais longe que os demais". Ele está constantemente atento a tudo que o cerca, é sempre muito curioso.

A equipe gerencial deve possuir a competência necessária para a transformação da oportunidade em resultados favoráveis à organização, sem que haja erros e gastos desnecessários. O comprometimento do empreendedor e da equipe gerencial também é importante. As pessoas não podem buscar apenas compensações financeiras, mas devem estar envolvidas de maneira a ter paixão e orgulho pelo que estão fazendo.

McMillian e Block (1997, citados por Birley; Muzyka, 2001) lembram o que pode ser considerado o mais importante fator de avaliação de uma oportunidade: o ajustamento da oportunidade com a estratégia e os objetivos da organização. "Se uma oportunidade for obviamente irreconciliável com a estratégia da companhia, então deve ser abandonada" (p. 272).

A oportunidade advém da criatividade e da inovação. A criatividade e a inovação são fatores cruciais para a sobrevivência de qualquer organização, sendo vistas como as principais vantagens competitivas atualmente. Como constatam Inácio Jr., Gomes e Caetano Jr., "para as empresas atuais, marcadas por um panorama de rápidas e complexas mudanças, riscos e incertezas, a habilidade de pensar e agir de forma diferente tem se tornado um dos recursos mais poderosos para gerar soluções originais" (2001 p. 2).

Ser criativo, porém, não é suficiente para gerar mudanças. É preciso ser inovador. Muitas vezes, confunde-se criatividade com inovação. Amabile (1997, apud Boro, 2004) diferencia criatividade de inovação de maneira simples: "criatividade é o primeiro passo para a inovação, que é a implementação bem-sucedida daquelas idéias apropriadas". Dornelas (2003) classifica a inovação em três categorias: idéias derivadas (adaptação/melhoria incremental de produtos, serviços e processos já existentes); nova plataforma (busca de novos mercados e novos negócios) e avançadas (inovações radicais e descontínuas, vinculadas a alto risco e retornos potenciais).

Os intra-empreendedores são agentes de mudança, pois trazem inovações à organização. Segundo Drucker (1995, citado por PESSOA, 2004, p. 4), "o empreendedor está sempre buscando a mudança. Reage a ela e a explora como sendo uma 'oportunidade'. Ele cria algo novo, age diferente, ele muda ou transforma valores. Ele inova".

Além da própria característica do empreendedor de habilidade de pensamento criativo, para que a atitude de mudança se concretize, deve haver abertura e incentivo da empresa à inovação (AMABILE, 1999, citada por Duarte, Silva; Almeida, 2002). As novas idéias apresentadas pelo intra-empreendedor podem ter uma resistência inicial na organização (Hashimoto, 2005, p.2). Para superar essa dificuldade, o intra-empreendedor deve utilizar sua habilidade de comunicação persuasiva. $\mathrm{O}$ empreendedor deve ter a capacidade de contagiar as pessoas com seus planos e idéias.

Pinchot e Pellman (2004) afirmam que a maioria dos intra-empreendedores trabalha em equipe, reunindo colaboradores com capacidades diversas. Cada membro da equipe deve compartilhar uma visão, trabalhar a serviço de uma causa comum.

Ângelo (2003, p. 158-159) trata da importância de criar uma rede de contatos pessoais (networking): "O contato com os colegas de outras áreas, o estabelecimento de um novo processo de sinergia e a 
conseqüente troca de experiências serão fatores importantes no processo de venda de novos projetos".

Os patrocinadores (também chamados de sponsors) também precisam ser conquistados. São eles que incentivam e facilitam a implantação da idéia na organização. Dornelas (2003, p. 72) define o sponsor como:

“...gerentes seniores, diretores ou outros funcionários de alto escalão, os quais agem como críticos e conselheiros do projeto, ajudando a equipe a conseguir os recursos e até mesmo interferindo e tentando modificar regras internas para que o projeto seja implementado. É o grande protetor do projeto internamente e o facilitador do processo".

Os intra-empreendedores também possuem habilidade de negociação. Berlew (1984, apud Carvalhal, 2001) define o termo : "negociação é um processo em que duas ou mais partes, com interesses comuns e antagônicos, reúnem-se para confrontar e discutir propostas explícitas com o objetivo de alcançarem um acordo". Os intra-empreendedores precisam utilizar habilidades de negociação para implementar suas idéias na organização. A disponibilização dos recursos necessários à concretização de um projeto envolve todo um processo de negociação, pois geralmente está em jogo o interesse da organização como um todo, envolvendo diversas áreas funcionais.

Ray (1993, apud MACEDO, 2003 p. 17) conceitua a habilidade de aquisição de informações como "saber coletar, reunir e agrupar informações de maneira a serem úteis em seu objetivo". O intra-empreendedor busca, por si mesmo, informações relacionadas à sua empresa (processos, produtos, pessoas), clientes, fornecedores, parceiros, concorrência, enfim, em relação a todos os stakeholders e ao ambiente que envolve a organização. As informações são utilizadas para melhorar o processo de negociação, de criatividade e inovação, para resolver problemas e para desenvolver

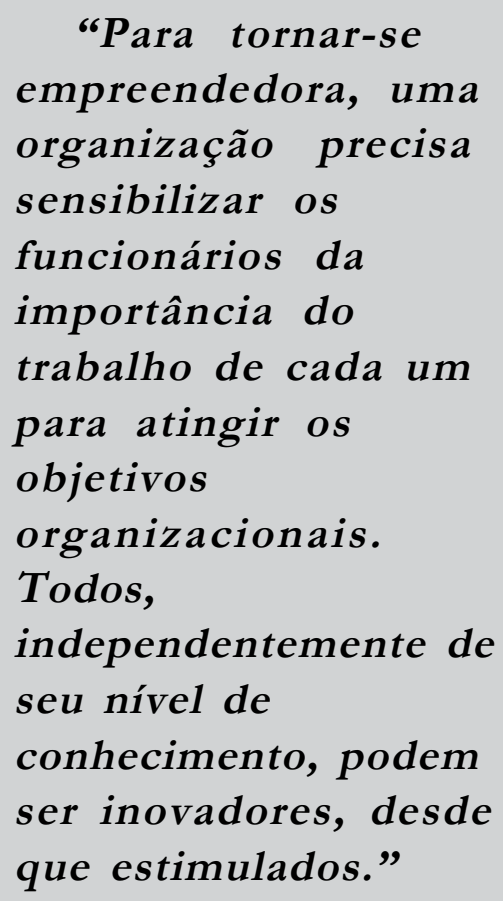

várias outras habilidades e competências necessárias ao empreendedor de sucesso. Podem ser adquiridas por meio de diversas fontes: jornais, revistas, televisão, palestras, Internet, observação direta da realidade ou mesmo de conselhos de pessoas que já passaram por posições similares na empresa ou fora dela.

O processo de resolução de problemas envolve, primeiramente, a criação de idéias, de soluções para os problemas já detectados. As soluções oferecidas pelos intraempreendedores podem ser de dois tipos: 
adaptadoras (com a tendência de melhorar o que já existe) e radicais (com a tendência de revolucionar o implantado e gerar soluções mais revolucionárias).

O empreendedor também possui a habilidade de alcançar metas, está sempre disposto a sacrificar-se ou despender esforço fora do comum para o alcance das metas estabelecidas por ele mesmo e cumprir compromissos assumidos. O próprio empreendedor tem a capacidade de estipular objetivos a longo prazo e metas a curto prazo para concretizar seus projetos.

Dornelas (2003) afirma que o empreendedor vai além da descrição do seu cargo, ou seja, além de suas responsabilidades pré-definidas e fazem o que for preciso para que seu projeto seja concretizado. Para atingir as metas da organização, os intra-empreendedores buscam na criatividade e na imaginação soluções viáveis, idéias que possam ser aproveitadas para que sua organização obtenha sucesso. "Eles [os intra-empreendedores] sonham acordados com formas de transformar idéias em realidade e visualizam maneiras de lidar com obstáculos em potencial", dizem Pinchot e Pellman (2004, p. 39). Ângelo (2003, p. 73) também considera a importância da imaginação: "a capacidade de imaginar é fundamental à execução de qualquer projeto. Trata-se de dar nitidez, volume e substância a uma idéia, de aproximar-se de sua essência".

A motivação e a tomada de decisão estão relacionadas ao caráter auto-motivado e autoconfiante do intra-empreendedor. Ele não teme tomar decisões por si só, quando necessário. Segundo Dornelas (2003, p. 63): "Eles não se sentem inseguros, sabem tomar as decisões corretas na hora certa, principalmente nos momentos de adversidade, sendo um fator-chave para o seu sucesso". Para que a habilidade de motivação e decisão seja utilizada, é necessário que a empresa tenha uma estrutura descentralizada, de modo que o poder de decisão não esteja somente sob a responsabilidade dos gerentes. As organizações que percebem a falha como fonte de experiência, aprendizado e progresso incentivam a tomada de decisão por parte dos intra-empreendedores e tornam o processo mais aberto, com maior liberdade. Porém, Dornelas (2003, p. 121) alerta: “a falha contínua deve ser evitada e até punida, quando a equipe não se espelha na experiência própria e dos outros no passado, não se preocupa com a utilização dos recursos e não se compromete com a organização".

O conjunto de capacidades e talentos que definem o intra-empreendedor decorre de fatores hereditários e do convívio social. Dessa forma, percebe-se a importância do desenvolvimento de uma cultura empreendedora nas organizações.

\section{A organização empreendedora}

As organizações, atualmente, precisam adotar uma gestão empreendedora para sobreviver e prosperar no contexto de grandes mudanças, de novas exigências e de alta competitividade. Não basta somente incluir, no discurso, conceitos de gestão empreendedora, se não houver coerência com as práticas adotadas. A cultura da organização contribui nesse processo, pois influencia e norteia as atitudes dos funcionários, desde os alto-executivos até os executores.

Conforme expõem Spinosa e Souza (2005, p. 08), “uma cultura favorável à formação de um espírito empreendedor provoca em seus empregados uma incessante busca pelo novo, pela melhor maneira de desenvolver algo (...), um constante aperfeiçoamento, uma conduta 
que leve à vantagem competitiva, incentiva a dedicação e o comprometimento, não só do corpo funcional, mas, principalmente (...) da alta direção".

A empresa empreendedora, antes de tudo, tem a alta cúpula envolvida com o processo. É preciso que os dirigentes aprovem o comportamento empreendedor e reconheçam a importância da proatividade e da inovação em suas organizações. Pereira (2005) afirma que "se não houver por parte da alta administração um comprometimento com o programa de empreendedorismo corporativo, é melhor nem começar". Segundo Dornelas (2003, p.118), “a organização deve ter um forte comprometimento com a busca e o desenvolvimento de novos produtos/serviços e processos, envolvendo a alta cúpula gerencial no suporte a essas iniciativas". Schenatto e Lezana (2001, p.4) afirmam:

"Cabe aos dirigentes [...] suscitar e dar espaço à vocação empreendedora interna, concentrando esforços também em buscar mais flexibilidade estrutural e agilidade nos processos burocráticos, a fim de reduzir os custos e dar suporte à ação inovadora permanente".

Além do comprometimento, a alta cúpula necessita integrar o empreendedorismo à estratégia corporativa. As empresas pró-ativas, estão incorporando ao seu planejamento estratégico a descentralização na tomada de decisão, visando a diminuição de custo operacional e elevação da qualidade dos produtos/ serviços que são ofertados com a participação direta de seus funcionários (ibidem).

Os gerentes e os chefes imediatos também possuem uma importante função na empresa empreendedora, já que são eles que fazem a ligação entre a alta cúpula e os funcionários da base da organização. Como diz Motta (1985 apud Souza et al., 2003, p.2), "uma organização empreendedora deve estar com lideres preparados e capacitados para gerenciar e isto significa: coordenar, ter visão de futuro [...], estimular a participação dos empregados, incentivar e motivar as pessoas em função de objetivos e metas compartilhadas, promovendo crescimento mútuo".

O próximo passo para que uma organização se torne empreendedora é sensibilizar os funcionários da importância do trabalho de cada um para atingir os objetivos organizacionais, despertando o espírito empreendedor. A inovação e o espírito empreendedor devem estar disseminados por toda a empresa. Todas as pessoas, independentemente de seu nível de conhecimento, podem ser inovadoras, desde que estimuladas. Baró (1983, apud SOUZA et al. 2003, p. 3) acredita que o trabalhador se motiva quando "conhece a importância do próprio trabalho para a organização". Dornelas (2003, p.52) sugere a utilização de programas de capacitação para esclarecer o conceito de empreendedorismo, "mostrando aos funcionários que todos poderão desenvolver esse espírito na empresa e que serão valorizados por isso". Pinchot e Pellman (2004) apontam a importância do compartilhamento da estratégia com os funcionários para estimular o intra-empreendedorismo.

Após incitar e promover atitudes empreendedoras também é preciso oferecer mecanismos para que as idéias geradas sejam avaliadas e, se possível, implementadas. Pinchot e Pellman (2004, p. 44) sugerem a criação de canais para que os intra-empreendedores exponham suas idéias. Dornelas (2003, p. 53) afirma que "de acordo com as necessidades da 
organização, essa estrutura ou programas internos devem ser moldados para focalizar não só o surgimento de idéias, mas de meios para implementá-las".

Finalmente, é importante verificar os resultados dos novos projetos. Os responsáveis por projetos que não deram certo não podem ser punidos, mas sim, incentivados a verificar os erros como parte de um processo de aprendizagem. Já, os projetos bem-sucedidos devem ser valorizados e recompensados.

Segundo Pinchot e Pellman (2004, p. 129), "quando as pessoas estão testando novas idéias e são punidas pelos 'erros' cometidos, há duas conseqüências negativas: as pessoas deixam de testar e os erros são ocultados. Assim, não há aprendizagem organizacional".

Entende-se, portanto, que as habilidades pessoais dos funcionários são importantes, mas, para que sejam desenvolvidas e utilizadas, deve existir apoio e fornecimento de condições favoráveis pela empresa. Um passo importante, então, é o conhecimento do perfil dos funcionários e a medição do potencial empreendedor de um modo geral. A proposta deste trabalho atende a essa etapa, visando identificar o grau de intra-empreendedorismo nos funcionários do cargo de PSA na Infraero, além de sugerir alternativas para o desenvolvimento e aproveitamento do potencial do corpo funcional pela organização.

\section{Metodologia}

Para a classificação da pesquisa, tomouse como base a tipologia apresentada por Vergara (2004), que propõe dois critérios quanto aos fins e quanto aos meios. Quanto aos fins, a pesquisa foi exploratória, porque a Infraero não havia efetuado ainda nenhuma pesquisa referente ao perfil intraempreendedor de seus funcionários até então. A pesquisa visou identificar o percentual de funcionários ocupantes de determinado cargo que possuem perfil intra-empreendedor, além de investigar quais características intra-empreendedoras aparecem com maior e menor freqüência e de elaborar sugestões de utilização e desenvolvimento do potencial empreendedor.

Quanto aos meios, a pesquisa foi bibliográfica e de campo. Foi realizada investigação sobre os seguintes assuntos: conceituação de empreendedorismo e empreendedorismo corporativo, importância do empreendedorismo no momento atual, principais características e o processo de implantação do empreendedorismo nas organizações. A pesquisa de campo foi efetuada por meio de questionário.

O instrumento utilizado na pesquisa de campo foi adaptado da dissertação de mestrado de Uriarte (2000). É composto de 28 itens, divididos em duas afirmações cada, sendo dois itens para cada característica intra-empreendedora. Foram utilizados dois itens para dificultar a possibilidade de escolha aleatória. $\mathrm{O}$ respondente, dentro de cada item, escolheu a firmativa que mais se aproximava de suas atitudes, de sua realidade. Os resultados foram analisados e compilados com o auxílio do programa Microsoft Excel 2000.

As características definidas como objeto de estudo nesta pesquisa foram as necessidades e as habilidades dos intraempreendedores. Não foram pesquisados os conhecimentos e valores por decisão das pesquisadoras de não avaliar os conhecimentos dos funcionários e também por serem altamente subjetivas as questões 
relativas a valores, tendo peso mínimo no cômputo geral da pesquisa, conforme Uriarte (2000).

\section{População/amostra}

A população da pesquisa de campo foi o corpo funcional da sede da -Infraero que ocupa o cargo de Profissional de Serviços Aeroportuários (PSA). As tarefas desenvolvidas pelo PSA são manuais e operacionais, de natureza rotineira. A execução das tarefas pressupõe o uso de aptidões pouco complexas. Os ocupantes dos demais cargos da empresa possuem funções mais complexas e atividades pouco rotineiras, exigindo-se constantemente tomada de decisões e proatividade. Tornou-se interessante, portanto, verificar se os funcionários ocupantes do cargo PSA possuem perfil empreendedor, para que se possam incentivar e desenvolver seu potencial para auxiliar a empresa na busca de soluções inovadoras.

$\mathrm{Na}$ empresa, existe a possibilidade de o profissional de serviços aeroportuários ocupar função de chefia ou de assumir a posição de assessor. Nesta pesquisa, selecionou-se para a amostra apenas os PSAs que não se enquadram nas duas situações acima. Portanto, a amostra é não-probabilística por tipicidade. A empresa possui 813 empregados do quadro lotados na sede da empresa. A população da pesquisa é formada por 297 empregados (o que equivale a 36,5\% do total de empregados). Aplicando-se os critérios de participação, a amostra seria composta de 215 empregados (72,4\% da população).

\section{Coleta e análise dos dados}

A pesquisa obteve retorno de 132 funcionários, de um total previsto de 215 funcionários. Essa diferença ocorreu devido a diversos fatores: funcionários lotados na sede da empresa, mas que fisicamente trabalham em outros estados da federação; afastamentos por motivo de viagem a serviço, férias ou licença médica; e questionários respondidos de maneira incompleta. A amostra efetivamente pesquisada equivale a $44,4 \%$ da população objeto de estudo.

\section{"A característica}

mais presente na

Infraero, quanto às

necessidades do

empreendedor, foi a

aprovação. Os

funcionários desejam

status e prestígio

perante os familiares,

amigos e colegas de

trabalho e também

consideram importante

o reconhecimento pelo

trabalho bem

executado."

Após o recolhimento dos questionários, foi feita a análise dos dados, comparando as respostas dos funcionários com as alternativas definidas como mais próximas do perfil intra-empreendedor. O grau de empreendedorismo dos funcionários foi identificado a partir da relação entre o número de itens respondidos e o número total de itens. Segundo Smoggi (2000, citado por URIARTE, 2000), se a porcentagem de conformidade ficou em até $60 \%$, o grau de 
empreendedorismo do funcionário é considerado baixo; entre $61 \%$ e $80 \%$, o grau de empreendedorismo é médio; se ficou acima de $80 \%$, o grau de empreendedorismo do funcionário é considerado alto.

\section{Dados da pesquisa com os funcionários}

Utilizando a categorização de Smoggi (2000, citado por URIARTE, 2000), foi realizada a distribuição dos funcionários em três níveis de intra-empreendedorismo: alto, médio e baixo, conforme Tabela 1 . respostas com perfil empreendedor em intervalos de $10 \%$.

Portanto, a grande maioria dos funcionários estudados possui grau de intra-empreendedorismo médio ou alto. Esses dados mostram que os PSAs da Infraero-sede possuem as características necessárias ao intra-empreendedor de sucesso. Basta desenvolver o espírito empreendedor, pois já existem aspectos, na personalidade dos funcionários pesquisados, compatíveis com as características do perfil intraempreendedor.

Tabela 1 - Grau de intra-empreendedorismo

\begin{tabular}{l|c|c}
\hline Grau & Freqüencia & Percentual \\
\hline Alto & 52 & $39,39 \%$ \\
\hline Médio & 68 & $51,52 \%$ \\
\hline Baixo & 12 & $9,09 \%$ \\
\hline TOTAL & 132 & $100,00 \%$ \\
\hline
\end{tabular}

Fonte: Dados da pesquisa

A porcentagem média de questões respondidas de acordo com o perfil intra-empreendedor foi de 75,16\%, o que equivale a 21,06 questões. A mediana, ou seja, o centro entre maiores e menores valores foi de $75 \%$, o equivalente a 21 questões. O desvio-padrão dentro da quantidade de respostas de acordo com o perfil intra-empreendedor foi de 0,12.

Entende-se, portanto, que a distribuição das respostas com perfil empreendedor ocorreu de forma simétrica. A amostra é homogênea e situa-se com maior freqüência com grau de empreendedorismo médio e alto. Essa afirmação pode ser demonstrada pelo Gráfico 1, que mostra o percentual de

\section{Características marcantes do perfil dos funcionários}

Foram também tabuladas as características mais e menos presentes dos participantes, trazendo de forma mais clara o seu perfil. Os Gráficos 2 e 3 mostram o resultado da pesquisa, de acordo com cada característica intra-empreendedora.

A característica que se fez mais presente, quanto às necessidades do empreendedor, é a de aprovação. Um total de $87,5 \%$ das respostas indica que os funcionários desejam status e prestígio perante os familiares, amigos e colegas de trabalho e também que consideram importante o reconhecimento pelo trabalho bem executado. $\mathrm{O}$ trabalho bem 


\section{Gráfico 1: Distribuição dos respondentes conforme o percentual de respostas com perfil empreendedor}

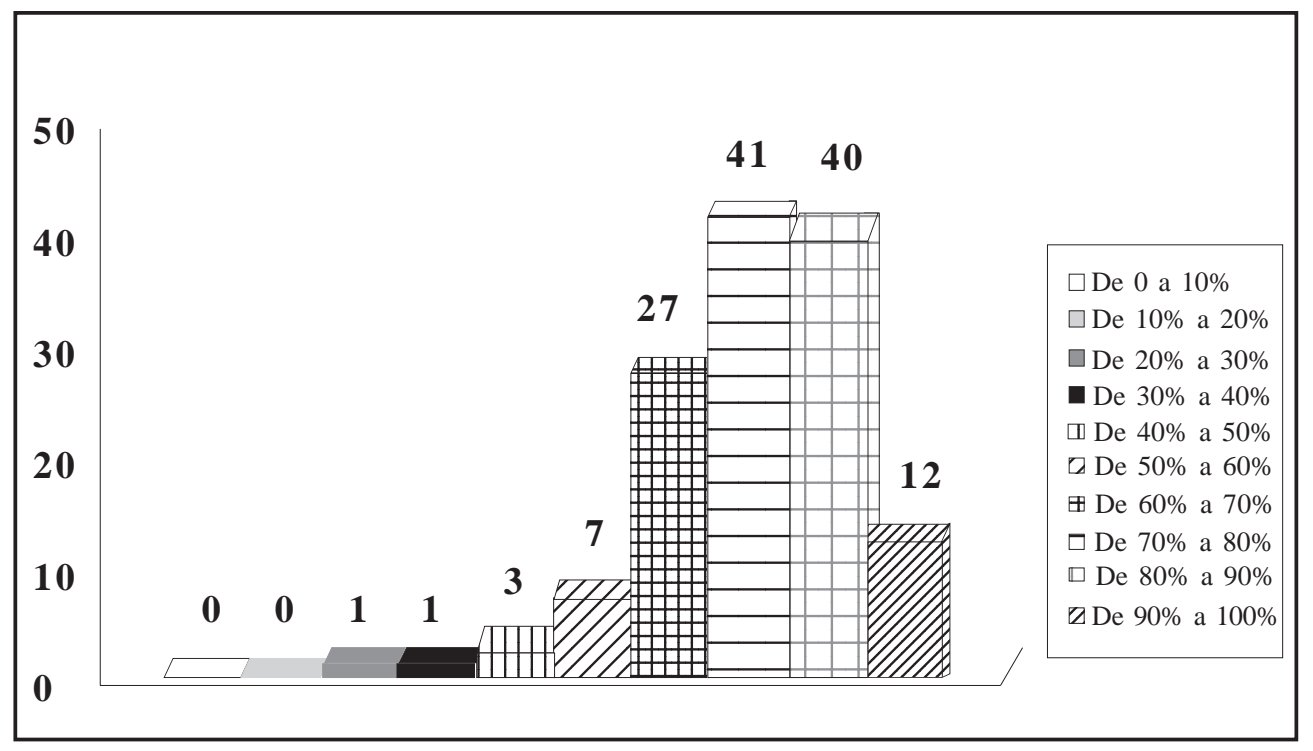

Fonte: Dados da pesquisa

executado e a dedicação dependem, portanto, de ações da empresa para que haja reconhecimento do trabalhador, não apenas na forma de premiação de projetos uma vez ao ano, mas de elogios e de recompensas em seu dia-a-dia.

A segunda característica mais presente, com $82,58 \%$ das respostas, é a necessidade de desenvolvimento pessoal. Os funcionários afirmaram que consideram necessário aprender continuamente e inovar, além de julgarem ser a empresa o local apropriado para desenvolvimento de novas habilidades. Para melhorar seu desempenho, é preciso que a empresa lhe informe em quais pontos ele pode melhorar, baseada em situações específicas. Fornecer feedback, conforme Dolabela (1999), de forma objetiva e clara, sem tom de censura, contribui para colaborar no aperfeiçoamento das capacidades.

A terceira característica mais verificada é a de vínculos: $80,3 \%$ das respostas apontam para a necessidade de aperfeiçoamento da capacidade dos trabalhadores dentro da empresa e da aplicação, na própria organização, das idéias que surgirem. O sentimento de vínculo com a organização só vem contribuir para os resultados da organização, pois o funcionário com essa característica geralmente envolve-se com as atividades com mais entusiasmo e disposição.

A característica menos presente é a necessidade de independência, com $54,55 \%$ das respostas. Apenas 58 trabalhadores informaram que necessitam de liberdade para desenvolver seu trabalho e 86 de flexibilidade na vida profissional. Percebe-se, com essa informação, que os participantes possuem uma tendência a não tomar iniciativa. De alguma forma, sentem-se presos à hierarquia e às normas internas, cumprindo o trabalho estritamente conforme solicitado. Esse é um ponto negativo identificado 
Gráfico 2: Percentual de respostas de acordo com as necessidades intra-empreendedoras

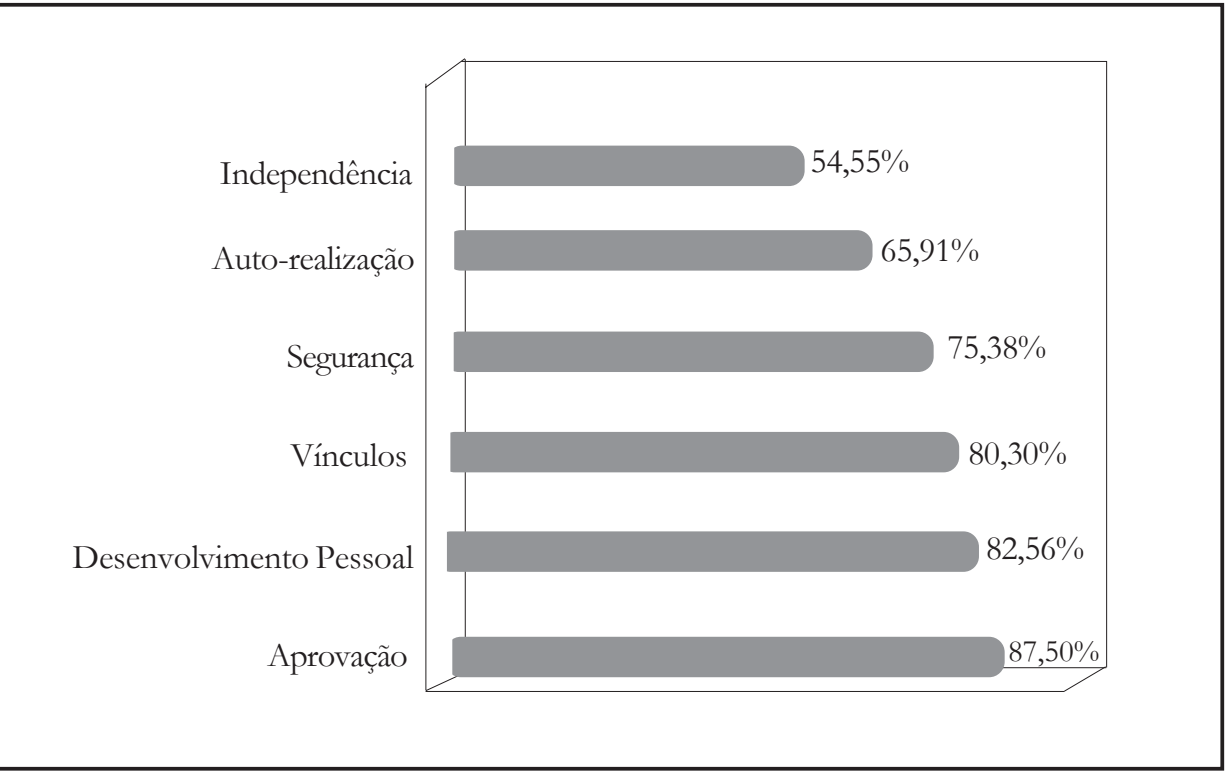

Fonte: Dados da pesquisa

no perfil dos funcionários, pois, dessa forma, não haverá motivação para explorar novos campos de trabalho e objetivos que eles mesmos poderiam estipular e seguir.

Outra característica pouco presente é a necessidade de auto-realização. Apenas 68 trabalhadores indicaram que se sentem realizados no ambiente de trabalho. Já 106 percebem a importância de possuírem outras capacidades, além daquelas necessárias ao cargo que ocupam. A falta de sentimento de realização no ambiente de trabalho faz com que eles não desempenhem suas atividades ao máximo de seu potencial, significando uma grande perda para a organização.

Essa situação necessitaria de uma pesquisa de satisfação no trabalho para que fossem identificados os motivos de insatisfação, que permita, depois, formular propostas de ação e aplicação.
Entre as habilidades pesquisadas (Gráfico 3), a que teve o maior número de respostas conforme o perfil intraempreendedor foi a de aquisição de informações (97,73\%). Quase a totalidade da amostra pesquisada (129 funcionários) possui a habilidade de adquirir conhecimentos por meio de diversos canais de informação, inclusive a Internet, considerada essencial, independente do campo de trabalho em que atuam. Dessa maneira, percebe-se que os trabalhadores têm facilidade de buscar informações, de conhecer mais. As informações são úteis em vários processos de intra-empreendedorismo, como negociação, resolução de problemas e criatividade. Trata-se de um resultado útil para a organização, que pode contar com colaboradoresdispostos a informarem-se cada vez mais e melhor.

A segunda habilidade mais presente (89,39\%) é a de valoração de oportunidades 
e pensamento criativo (Gráfico 3). Muitos informaram ser importante avaliar as oportunidades que surgem, analisando os pontos positivos e negativos antes de investir nelas. Essa característica também é importante, pois os trabalhadores não demandam esforço nem tempo por oportunidades que não são viáveis à organização. Já a criatividade e a inovação são essenciais ao processo de intraempreendedorismo: a essência do empreendedorismo é a criação de boas idéias e sua implantação para a melhoria incremental ou radical de processos, produtos, serviços e dos resultados, de modo geral. Cabe à organização incentiválas, criando mecanismos para a maior participação dos funcionários. problemas, sem ter que delegar a responsabilidade a outras pessoas, e também a de geração de soluções inovadoras, não deixando que tudo se resolvesse com o tempo. A habilidade detectada tem forte ligação com a de pensamento criativo, pois surgirão soluções para os problemas, a partir de idéias geradas por todos na organização. Cada um pode contribuir nesse processo, independentemente de seu cargo.

Um resultado foi bastante diferente dos demais: apenas 48,86\% das respostas indicam a habilidade de motivação e decisão. Apenas 72 trabalhadores afirmaram que são autoconfiantes e automotivados e somente 57 não receiam tomar decisões sozinhos, quando necessário. Isso pode ocorrer devido à falta de

\section{Gráfico 3: Percentual de respostas de acordo com as habilidades intra-empreendedoras}

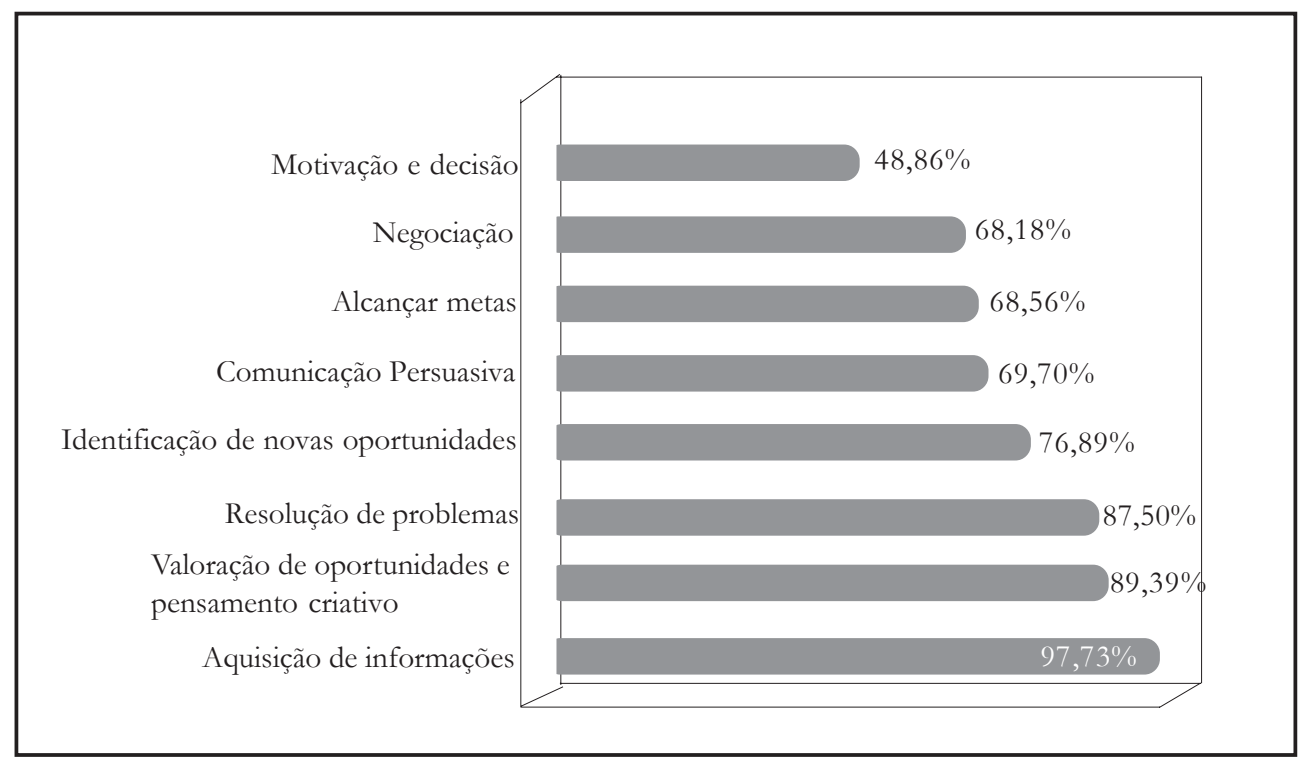

Fonte: Dados da pesquisa

A terceira habilidade mais identificada é a de resolução de problemas $(87,5 \%)$. Muitos indicaram a habilidade de resolver abertura da empresa para que eles tomem decisões sozinhos, mesmo que erradas. Dornelas (2003) e diversos outros autores 
apontam para a necessidade de a organização perceber a falha como fonte de experiência, evitando e punindo somente as falhas contínuas que possam comprometer a organização.

\section{Considerações finais}

Cada vez mais, a importância de uma gestão empreendedora nas organizações é percebida e aceita. Sem o empreendedorismo, não só no discurso como também na prática, não há como as empresas sustentarem-se no mercado, bem como manter a credibilidade, os resultados financeiros e o nível de satisfação dos stakeholders.

Percebe-se, com o resultado $\mathrm{da}$ pesquisa, que deve haver esforço tanto por parte dos funcionários, como por parte da organização para que o espírito empreendedor se perpetue. Os trabalhadores possuem características empreendedoras imprescindíveis, porém precisam desenvolver outras características, também importantes, para que possam exercer o empreendedorismo na Infraero. É necessário, por exemplo, que desenvolvam também a iniciativa e a independência para que possam melhor colaborar com a organização e e obtenham realização pessoal.

A empresa pode adotar diversas ações de forma a aumentar a participação dos funcionários. Uma delas é a maior disseminação das informações da organização a todos os colaboradores. Os objetivos e estratégias, além dos resultados alcançados, devem ser informados constantemente, de maneira que todos tenham conhecimento da situação da empresa e do que pode ser feito para contribuir mais efetivamente.

Também é sugerido que a Infraero dê maior liberdade para a ação dos seus colaboradores, admitindo erros como parte do processo de aprendizagem. Os gerentes podem auxiliar nesse processo, permitindo que os PSAs participem da tomada de decisões importantes. Para maior aprofundamento do estudo, sugerese que sejam feitas pesquisas de satisfação, no ambiente organizacional, com os profissionais de serviços aeroportuários, visando aferir os motivos de insatisfação e implantar ações que façam com que os colaboradores vejam seu trabalho como fonte de realização pessoal.

Também considera-se necessário aumentar a extensão da pesquisa para outros cargos, o que possibilitaria avaliar se a situação apresentada para os PSAs da sede da empresa também verifica-se de forma geral na organização.

Conclui-se ratificando a importância das características intra-empreendedoras nos funcionários de qualquer organização. O empreendedorismo move as organizações em direção a novas formas de gestão, à proatividade e à manutenção da qualidade de atendimento ao cidadão. Sem os trabalhadores, sem o capital intelectual da organização, não é possível o sucesso de uma organização.

(Artigo recebido em setembro de 2006. Versão final em dezembro de 2006) 


\section{Referências bibliográficas}

AıUB, G. W. Inteligência empreendedora: uma proposta para a capacitação de multiplicadores da cultura empreendedora. Dissertação, Mestrado em Engenharia da Produção, Universidade Federal de Santa Catarina, Florianópolis, SC, 2002.

ÂNGELO, E. B. Empreendedorismo: a revolução do novo Brasil. Disponível em: < http:/ / www.faap.br/revista_faap/rel_internacionais/empreendedorismo.htm $>$. Acesso em: 20 mar. 2005.

- Empreendedor corporativo: a nova postura de quem faz a diferença. Rio de Janeiro: Campus, 2003.

ASSOCIAÇÃo BRASILEIRA DE NoRMAS TÉCNICAS. NBR 6023: informação e documentação: referências - elaboração. Rio de Janeiro: Autor, 2002 a.

. NBR 10520: informação e documentação: citações em documentos - apresentação. Rio de Janeiro: Autor, 2002 b.

Birley, S., \& Muzyka, D. F. Dominando os desafios do empreendedor. São Paulo: Makron Books, 2 ed, 2001.

Boro, M. A. A criatividade e a inovação como fator de criação de valor e vantagem competitiva. Disponível em: <www.fdc.org.br/pdf/ CI0409.pdf>. Acesso em: 15 mar. 2005.

Braga, J. N. P. O empreendedorismo como instrumento de desenvolvimento - o programa IES, SOFTEX. Dissertação, Mestrado em Administração, Universidade Federal da Bahia, Salvador, BA, 2003.

Brasil. Resolução n $n^{0}$ 12, de 30 de outubro de 2003. Da infra-estrutura aeroportuária Exportação de serviços. Diário Oficial [da] República Federativa do Brasil, Poder Executivo, Ministério da Defesa- Conselho de Aviação Civil, Brasília, DF, 8 nov. 2003, Seção 1, p.8, 2003.

Carvalhal, E. do. (2001). Negociação: fortalecendo o processo. São Paulo: Vision.

Chinvenato, I. Teoria geral da administração. 6a ed, v.2. Rio de Janeiro: Campus, 2002

Cozzi, A. O.; Arruda, C. Desenvolvendo a capacidade empreendedora de uma organização. Disponível em: <http://www.fdc.org.br/pt/sala_ conhecimento / exibe_documento.asp? CodMenu=15\&CodDocumento=61>. Acesso em: 20 dez. 2004. Danroco, E.; Carnelutti, J. G.; Furian, N. G. Empreendedorismo: uma análise nas instituições particulares do Rio Grande do Sul. In 5. Encontro Nacional de Empreendedorismo, 2003, Florianópolis, SC. Disponível em <www.ene.ufsc.br/enempre2003> Acesso em: 15 mar. 2005.

DiAs, E. L. Um estudo comparativo entre empreendedores e intraempreendedores sobre os valores referentes ao trabalho. Dissertação, Mestrado em Engenharia de Produção, Universidade Federal de Santa Catarina, Florianópolis, SC, 2001.

Dolabela, F. A metodologia pedagogia empreendedora. Disponível em: <www.dolabela.com.br/ artigos.asp>. Acesso em: 02 mar. 2005.

O segredo de Luisa. São Paulo: Cultura, 1999. 
Dornelas, J. C. A. Empreendedorismo corporativo: como ser empreendedor, inovar e se diferenciar em organizações estabelecidas. Rio de Janeiro: Elsevier, 2003.

Duarte, E. F.; Silva, F. P. ; Almeida, A. L. de. A criatividade e o empreendedor. o diferencial no mercado de trabalho. In: $4^{\circ}$ Encontro Nacional de Empreendedorismo, Florianópolis, SC, 2002. Disponível em: <www.ene.ufsc.br>. Acesso em: 18 mar. 2005.

Наsнimoто, M. As dificuldades do empreendedor interno. Disponível em: $<$ www.administradores.com.br/colunas.jsp?idColuna $=150 \&$ idColunista $=26>$ Acesso em: 02 fev. 2005.

Porque as empresas precisam incentivar o empreendedorismo corporativo. Disponível em: <http://groups.msn.com/marcoshashimoto porqueoempreendedorismointerno.msnw>. Acesso em: 12 dez. 2004.

InÁCio Jr, E.; Gomes, G. C.; Caetano Jr, J. M. V. Como o empreendedorismo tem se associado à criatividade e liderança: algumas proposições sobre estas relações. In: $2^{\circ}$ Encontro de Estudos sobre Empreendedorismo e Gestão de Pequenas Empresas, 2001, Londrina, PR. Disponível em: <www.ppa.uem.br/egepe.htm>. Acesso em: 04 mai. 2005.

Infraero. Código de ética empresarial. Brasília, DF: Disponível em: <www.infraero.gov.br> . 2004 a. Acesso em: 05 mar. 2005.

Relatório da Administração 2004. Brasília, DF: Disponível em: <http:// www.infraero.gov.br/inst_resu.php?gi=instresufina\&menuid=inst $>$. Acesso em: 25 mar. 2005.

Leite, E. A visão integrada do fenômeno do empreendedorismo. Disponível em: <www.anprotec.org.br/habitats/trabalho/A.06.pdf>. Acesso em: 10 jun.2005.

MAcedo, M. O estudo do perfil empreendedor nas empresas familiares. Dissertação, Mestrado em Engenharia de Produção, Universidade Federal de Santa Catarina, Florianópolis, SC, 2003.

Moreira, E. G. O intra-empreendedorismo como competência organizacional. Disponível em: <www.fa7.edu.br/rea7/iniciacao_cientifica/arquivos/Erbene.doc>. Acesso em: 12 abr. 2005

Pereira, C. Empreendedorismo hoje é questão de sobrevivência. Disponível em: <www.ric.com.br/ entrevista_pereira.asp>. Acesso em: 20 fev. 2005.

Pessoa, E.; Goulart, S. Administração empreendedora: uma abordagem comportamental. In: ENANPAD - Encontro da Associação Nacional de Pós-Graduação e Pesquisa em Administração, 2004, Curitiba, PR.

PessoA, E. Empreendedorismo, uma questão de atitude (apostila). Brasília, DF, 2004.

Pinchot, G.; Pellman, R. Intra-empreendedorismo na prática: um guia de inovação nos negócios. Rio de Janeiro: Elsevier, 2004.

SAYED, K. M. E. A negociação no processo de gestão empresarial: da necessidade à arte. Disponível em: <www.fae.edu/ publicacoes/pdf/revista_fae_business/n7/rev_fae_ business_07_2003_gestao_12.pdf>. Acesso em: 02 jun. 2005. 
Schenatto, F. J. A.; LeZANA, A. G. R. O intraempreendedor como agente de mudança nas instituições públicas federais de educação superior. In: $21^{\circ}$ Congresso Brasileiro de Ensino de Engenharia, 2001, Porto Alegre, RS. Disponível em: <http://www.pp.ufu.br/Cobenge2001/ trabalhos/ EMP001.pdf>. Acesso em: 01 mar. 2005.

Silva, W. R., SAles, J. D. A. ; Souto, J. V. Fatores que influenciaram as pessoas a abrirem seus próprios negócios: o estudo de caso da UFPB. In: $7^{\circ}$ Seminário em Administração, 2004, São Paulo. Disponível em: <www.fea.usp.br/Semead/7semead/ paginas/ $\operatorname{artigos} \% 20$ recebidos/RH/RH23_-_Fatores_que_influenciaram_abrirem_propr.pdf $>$. Acesso em: 20 mar. 2005.

SouzA, E. B. de et al. Estratégias para uma gestão organizacional empreendedora. In: $5^{\circ}$ Encontro Nacional de Empreendedorismo, 2003, Florianópolis, SC. Disponível em: <http:// www.ene.ufsc.br/enempre_anais/ANAIS/45.pdf>. Acesso em: 20 fev. 2005.

SpinosA, L. M.; SouZA, R. C. de. Um modelo de empreendedorismo integrado aos conceitos de classe mundial. Disponível em: <www.aplicaciones.icesi.edu.co/ciela/anteriores/Papers/emcor/ 3.pdf>. Acesso em: 15 jun. 2005.

URIARTE, L. R. Identificação do perfil intraempreendedor. Dissertação, Mestrado em Engenharia de Produção, Universidade Federal de Santa Catarina, Florianópolis, SC, 2000.

Vergara, S. C. Projetos e relatórios de pesquisa em administração (5a ed.). São Paulo: Atlas, 2004. 


\section{Resumo - Resumen - Abstract}

\section{Perfil intra-empreendedor: um estudo inicial em funcionários da Infraero-sede Eliana Pessoa e Kelly Cristina Nóbrega Oliveira}

Considerando os conceitos de intra-empreendedorismo e sua importância para as organizações atualmente, realizou-se pesquisa juntos aos ocupantes do cargo de Profissional de Serviços Aeroportuários (PSA), na sede da Empresa Brasileira de Infra-Estrutura Aeroportuária (Infraero), buscando verificar se eles possuem ou não perfil intra-empreendedor. Utilizou-se um questionário, composto de 28 questões referentes às necessidades e habilidades indispensáveis ao desenvolvimento do intra-empreendedorismo, para avaliar o perfil dos funcionários, bem como levantar as características que apareceram com maior e menor freqüência na amostra selecionada. Como resultado, concluiu-se que a maioria dos empregados pesquisados possui perfil intra-empreendedor, porém necessitando do desenvolvimento de outras características, tais como necessidade de independência e de autorealização, também imprescindíveis. Foram sugeridas, também, ações que podem ser adotadas na organização para incentivar os trabalhadores a exercer suas capacidades empreendedoras.

Palavras-chave: intra-empreendedorismo; capacidade empreendedora; perfil intra-empreendedor; Infraero.

\section{Perfil intrapreneur: un estudio inicial en empleados de la Infraero-jefatura Eliana Pessoa y Kelly Cristina Nóbrega Oliveira}

En vista de los conceptos de intrapreneuring y de su importancia en las organizaciones actualmente, el perfil de los ocupantes de la posición de Profesional de Servicios de Aeropuertos (PSA), fue investigado en la jefatura de la Empresa Brasileña de Infraestructura Aeroportuaria (Infraero), intentando verificar si los ocupantes de esta posición tienen o no el perfil del intrapreneur. Un cuestionario, con 28 preguntas, fue utilizado para identificar las necesidades y las capacidades imprescindibles al desarrollo del intrapreneuring, buscando la evaluación del perfil de los empleados, así como las características que surgieron con mayor y menor frecuencia en la muestra seleccionada. Se concluyó que la mayoría de los empleados investigados tiene el perfil del intrapreneur, pero necesita del desarrollo de otras características como autonomía e auto-realización, también esenciales. Fueron sugeridas, también, las acciones que se pueden adoptar en la organización para estimular a los empleados a ejercer sus capacidades emprendedoras.

Palabras claves: intrapreneuring; capacidade empreendedora; perfil del intrapreneur; Infraero.

\section{Intrapreneur profile: an initial study with employees at Infraero-headquarters Eliana Pessoa and-Kelly Cristina Nóbrega Oliveira}

In the light of the concepts of intrapreneuring and of its importance for the organizations today, this study outlines the profiles of the Airport Services Professionals (PSA) at the headquarters of Infraero - Brazilian Airports, trying to verify whether they present or not an intrapreneur profile. A questionnaire of 28 questions was used to identify indispensable needs and abilities to foster the 
development of intrapreneuring, aiming to assess the employees' profiles, as well as the features that that appeared the most and the least frequently in the selected sample. The result points that the majority of the selected employees has an intrapreneur profile, requiring, however, the development of other characteristics such as self- reliance and self-accomplishment, also considered essential. The article concludes by suggesting sets of actions that can be adopted by the organization to stimulate the exercise of the employees' enterprising capacities.

Key-words: intrapreneuring; enterprising capacity; intrapreneur profile; Infraero.

Eliana Pessoa

Professora da UnB e da Unieuro, mestranda em Educação, Bacharel em Administração de Empresas. Contato: <elianapes@gmail.com.>

Kelly Cristina Nóbrega Oliveira

Bacharel em Administração de Empresas pela UnB. Contato: <kellycnoliveira@yahoo.com.br> 